\title{
Predicting Mean and Bankfull Discharge from Channel Cross-Sectional Area by Expert and Regression Methods
}

\author{
Gokmen Tayfur · Vijay P. Singh
}

Received: 29 April 2010 / Accepted: 18 November 2010 /

Published online: 3 December 2010

(C) Springer Science+Business Media B.V. 2010

\begin{abstract}
This study employed four methods-non-linear regression, fuzzy logic (FL), artificial neural networks (ANNs), and genetic algorithm (GA)-based nonlinear equation-for predicting mean discharge and bank-full discharge from crosssectional area. The data compiled from the literature were separated into two groups - training (calibration) and testing (verification). Using training data sets, the methods were calibrated to obtain optimal values of the coefficients of the non-linear regression method; optimal number of fuzzy subsets, their base widths and fuzzy rules for the fuzzy method; and the optimal number of neurons in the hidden layer, the learning rate and momentum factor values for the ANN model. The GA-based method employed 100 chromosomes in the initial gene pool, $80 \%$ cross over rate and $4 \%$ mutation rate in determining the optimal values of the coefficients of the constructed nonlinear equation. The calibrated methods were then applied to the test data sets. The test results showed that the non-linear regression, ANN and GA-based methods were comparable in predicting the mean discharge while the fuzzy method produced high errors and low accuracy. The GA-based method had the highest accuracy of $75 \%$. In terms of predicting bankfull discharge, all methods produced satisfactory results, although the fuzzy method had the lowest accuracy of $33 \%$. The results of sensitivity analysis, which is limited to the GA-based and nonlinear regression methods, showed that the GA-based method calibrated with low bankfull discharge values can be successfully applied to predict high bankfull discharge values. This has important implications for predicting bankfull rates at ungauged sites. On
\end{abstract}

G. Tayfur $(\bowtie)$

Department of Civil Engineering, Izmir Institute of Technology, Urla,

Izmir, 35340, Turkey

e-mail: gokmentayfur@iyte.edu.tr

V. P. Singh

Department of Biological \& Agricultural Engineering, Texas A \& M University,

College Station, TX 77843-2117, USA

e-mail: vsingh@tamu.edu 
the other hand, the sensitivity analysis results also showed that both the non-linear regression and GA-based methods have poor extrapolation capability for predicting mean discharge data.

Keywords River $\cdot$ Mean discharge $\cdot$ Bank-full discharge $\cdot$ Cross section • Regression $\cdot$ ANN $\cdot$ Fuzzy $\cdot$ Genetic algorithm

\section{Introduction}

Floods are natural disasters that can cause great economic damage, and loss of life and livelihoods. Estimation of discharge is vital and hence it has been a focus of research for decades. Researchers have developed several methods for this purpose including the regression-based (Engeland and Hisdal 2009; Eslamian et al. 2010; among others) and the soft computing methods (Zhu and Zhou 2009; Akbari et al. 2009; Chen et al. 2010; among others).

At ungauged sites, the regression-based approaches are often employed to estimate flood flows (Wharton et al. 1989; Wharton and Tomlinson 1999; Bhatt and Tiwari 2008). When information on catchment characteristics is limited, the channel geometry method, which relates streamflow data using regression analysis, is often employed for estimating flood discharge (Wahl 1984; Wharton 1995, among others). Williams (1978) constructed regression equations relating bankfull discharge to channel cross section and slope. Hey and Thorne (1986) related bankfull discharge to channel width, and slope. Bhatt and Tiwari (2008) constructed several regression equations relating streamflow discharge to channel width, flow depth, channel cross section, and a combination of catchment area, slope, mean channel length, and mean annual rainfall.

Channel geometry equations which relate discharge to channel width or channel cross section are considered to be the most reliable. Bhatt and Tiwari (2008) developed regression equations relating discharge to channel cross section to yield the most satisfactory results. Once hydraulic geometry equations are defined for a stream, the cross-section area measurement is all that is needed for estimating the discharge at an ungauged river site.

The objective of this study is to develop four methods for estimating flow discharge and flow bankfull discharge using only the corresponding cross sectional area. These methods include non-linear regression equation (RE), artificial neural networks (ANNs), fuzzy logic (FL), and a nonlinear equation whose coefficients are obtained by a genetic algorithm (GA-based). Most of the previous studies involving regression equations used either the whole or most of the data sets for calibration and did not spare many data for verification. For example, Bhatt and Tiwari (2008) used only seven out of 42 data (about 17\%) for testing. For a method to be reliable, at least $1 / 3$, if not half or more, of data need to be used for verification. This study separated the data sets into calibration and testing groups with about, on the average, $65 \%$, and $35 \%$ respectively. Literature shows that expert methods, such as ANNs, FL, GAs, do not seem to have been employed for discharge estimation at ungauged sites using only the cross sectional area data. This study also investigates the extrapolation ability of the non-linear regression and GA-based methods which is crucial for predicting flows at ungaguged basins. 
Table 1 Statistical summary of the whole data sets

\begin{tabular}{lcccc}
\hline & $\mathrm{A}\left(\mathrm{m}^{2}\right)$ & $\mathrm{Q}\left(\mathrm{m}^{3} / \mathrm{s}\right)$ & $\mathrm{A}_{\mathrm{b}}\left(\mathrm{m}^{2}\right)$ & $\mathrm{Q}_{\mathrm{b}}\left(\mathrm{m}^{3} / \mathrm{s}\right)$ \\
\hline Mean & 202.7 & 142.5 & 55.4 & 103.5 \\
Minimum & 10.1 & 2.4 & 10.9 & 5.2 \\
Maximum & 1010 & 915.6 & 407.8 & 736.3 \\
Standard deviation & 205.9 & 170.5 & 65.0 & 125.6
\end{tabular}

\section{Data}

Mean cross-sectional area (A) and mean discharge $(\mathrm{Q})$ data were compiled from Tayfur (2006) and Bhatt and Tiwari (2008). 68 sets of data, taken from Tayfur (2006), consist of hydraulic and geometric features of 30 rivers from the U.S. The width to depth ratio of the rivers varied between about 14 to $157 \mathrm{~m}$. The channel shape parameter varied from 2.62 to 5.05, implying a stream with a flatbed region and two curving banks. 41 sets of data, taken from Bhatt and Tiwari (2008), are from 40 bridge sites comprising small and medium-sized catchments ranging from 30 to $2,111 \mathrm{~km}^{2}$ in area. The bridge sites are located on different rivers in central and south India. For analysis, only cross sectional areas equal or larger than $10 \mathrm{~m}^{2}$ were considered. A statistical summary of the 109 data sets is presented in Table 1.

The bankfull cross-sectional area $\left(\mathrm{A}_{\mathrm{b}}\right)$ and bankfull discharge $\left(\mathrm{Q}_{\mathrm{b}}\right)$ data were compiled from Williams (1978), and Hey and Thorne (1986). Williams (1978) obtained data from 28 gauged sites in the western United States. The sites represent a wide range of climatic and geographic conditions. Hey and Thorne (1986) collected data from 60 sites located on several streams in the United Kingdom. In this study, a cross-section whose area was less than $10 \mathrm{~m}^{2}$ was not considered. A total of 89 sets of data were employed. A statistical summary of these data sets is presented in Table 1.

\section{Development and Application of Methods}

\subsection{Non-linear Regression Method}

The relation between mean discharge and mean cross sectional area is generally a nonlinear relation of kinematic wave type expressed as of $Q=\beta A^{\alpha}$, where $\alpha$ and $\beta$ are parameters. Since the variation in the data is large, as seen from Table 1 , the data were log-transformed as

$$
\log (Q)=\alpha \log (A)+\log (\beta)
$$

Table 2 Statistics of calibration (Training) and verification (Testing) data sets

\begin{tabular}{|c|c|c|c|c|c|c|c|c|}
\hline & \multicolumn{2}{|c|}{ Calibration set } & \multicolumn{2}{|c|}{ Verification set } & \multicolumn{2}{|c|}{ Calibration set } & \multicolumn{2}{|c|}{ Verification set } \\
\hline & $\mathrm{A}\left(\mathrm{m}^{2}\right)$ & $\mathrm{Q}\left(\mathrm{m}^{3} / \mathrm{s}\right)$ & $\mathrm{A}\left(\mathrm{m}^{2}\right)$ & $\mathrm{Q}\left(\mathrm{m}^{3} / \mathrm{s}\right)$ & $\overline{A_{b}\left(m^{2}\right)}$ & $\mathrm{Q}_{\mathrm{b}}\left(\mathrm{m}^{3} / \mathrm{s}\right)$ & $\mathrm{A}_{\mathrm{b}}\left(\mathrm{m}^{2}\right)$ & $\mathrm{Q}_{\mathrm{b}}\left(\mathrm{m}^{3} / \mathrm{s}\right)$ \\
\hline Mean & 192.1 & 132.6 & 224.4 & 162.5 & 49.7 & 97.9 & 66.6 & 114.0 \\
\hline Minimum & 10.1 & 2.4 & 11.7 & 3.1 & 10.9 & 5.2 & 12.5 & 8.2 \\
\hline Maximum & 715.6 & 915.6 & 1010 & 811.8 & 335.4 & 736.3 & 407.8 & 668.4 \\
\hline St. deviation & 195.0 & 166.5 & 228.5 & 180.5 & 55.0 & 122.5 & 0.5 & 132.2 \\
\hline
\end{tabular}

$A$ mean cross sectional area; $Q$ mean discharge; $A b$ bankfull cross sectional area; $Q b$ bankfull discharge 


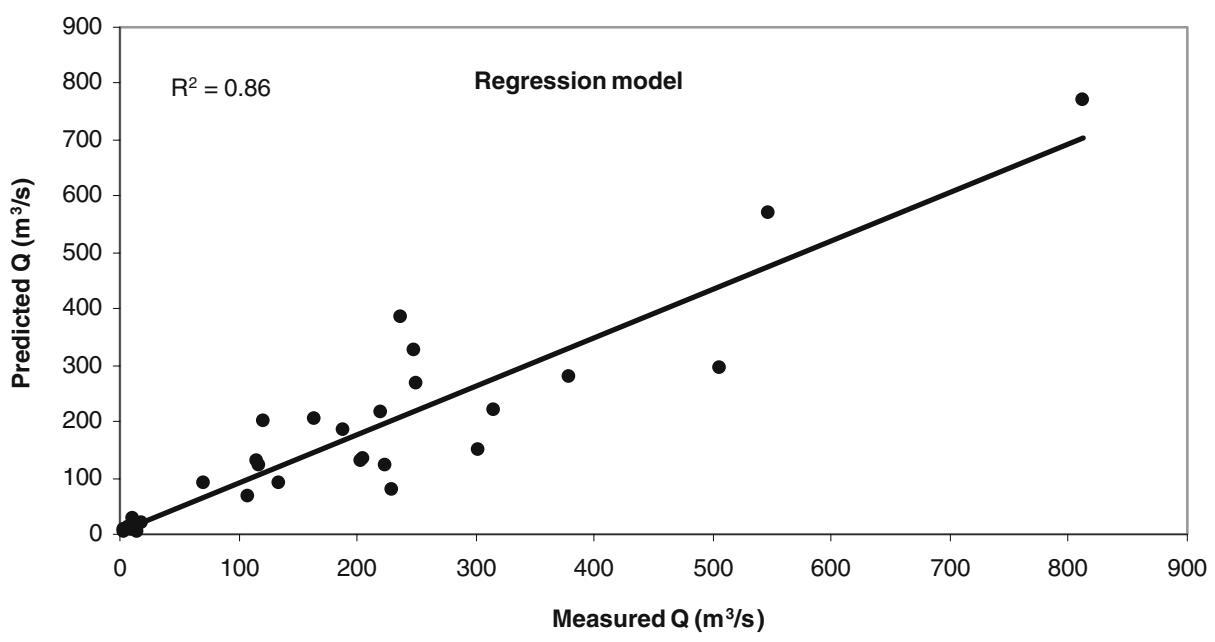

Fig. 1 Measured versus predicted mean discharge by the regression method

Data were separated into calibration and validation sets. The calibration set contained 73 data, while the validation set had the remaining 36 sets. Statistics of the calibration and validation sets are summarized in Table 2 . The regression equation obtained for the calibration set was $\left(\mathrm{R}^{2}=0.89\right)$ :

$$
\log (Q)=1.1774 \log (A)-0.6508
$$

Equation 2 was tested using the validation data set (Fig. 1). The mean absolute error (MAE) and the mean relative error (MRE) and $\mathrm{R}^{2}$ values for Fig. 1 are summarized in Table 3. Also provided there is the accuracy of the method. The accuracy of a method may be defined by the number of discrepancy ratio $(D R)\left[D R=\log \left(\frac{Q_{\text {pred }}}{Q_{\text {meas }}}\right)\right]$ values between -0.18 and 0.18 , which corresponds to $50 \%$ under prediction and $50 \%$ over prediction respectively, relative to the total number of data values.

Eighty-ninee bankfull discharge $\left(\mathrm{Q}_{\mathrm{b}}\right)$ and bankfull cross sectional area $\left(\mathrm{A}_{\mathrm{b}}\right)$ data were separated into $59(66 \%)$ for calibration and $30(34 \%)$ for verification. The corresponding statistics are summarized in Table 2 . The regression equation obtained for the calibration set with $\mathrm{R}^{2}=0.79$ was:

$$
\log \left(Q_{b}\right)=1.1898 \log \left(A_{b}\right)-0.0773
$$

\begin{tabular}{|c|c|c|c|c|c|c|c|c|}
\hline & \multicolumn{4}{|c|}{ Mean Discharge $\left(\mathrm{m}^{3} / \mathrm{s}\right)$} & \multicolumn{4}{|c|}{ Bankfull Discharge $\left(\mathrm{m}^{3} / \mathrm{s}\right)$} \\
\hline & Regression & GA-based & Fuzzy & ANN & Regression & GA-based & Fuzzy & ANN \\
\hline MAE & 43.5 & 50.1 & 63.8 & 46.6 & 49.1 & 56.3 & 44.3 & 35.6 \\
\hline MRE \% & 33 & 37 & 138.3 & 56 & 60.0 & 69.0 & 64.0 & 69.0 \\
\hline $\mathrm{R}^{2}$ & 0.86 & 0.86 & 0.81 & 0.86 & 0.89 & 0.89 & 0.86 & 0.86 \\
\hline Accuracy \% & 64 & 75 & 40 & 63 & 67 & 60 & 33 & 73 \\
\hline
\end{tabular}

Table 3 Computed errors for predictions of the verification data sets

$M A E$ mean absolute error $\left(\mathrm{m}^{3} / \mathrm{s}\right), M R E$ mean relative error $(\%)$ 


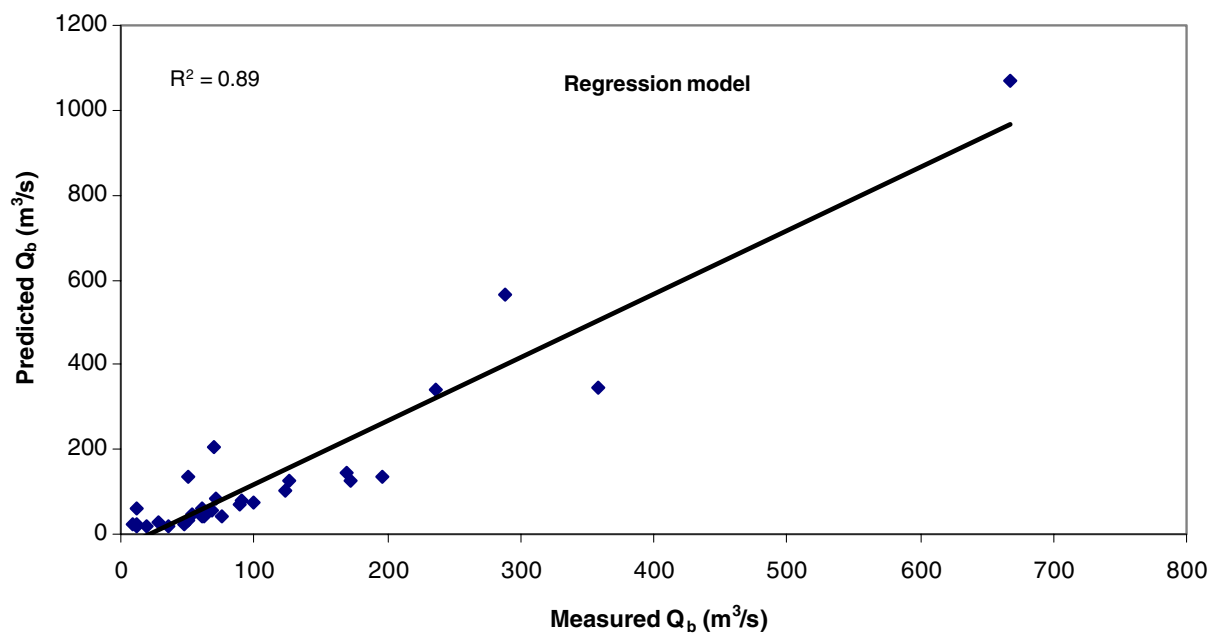

Fig. 2 Measured versus predicted bankfull discharge by the regression method

Equation 3 was tested using the verification data set (see Fig. 2). The computed error measures and accuracy rate for Fig. 2 are also summarized in Table 3.

\subsection{Genetic Algorithm-Based Method}

A genetic algorithm (GA) is a nonlinear search and optimization method inspired by biological processes of natural selection and the survival of the fittest. Basic units of GA consist of 'bit', 'gene', 'chromosome' and 'gene pool'. Gene consisting of

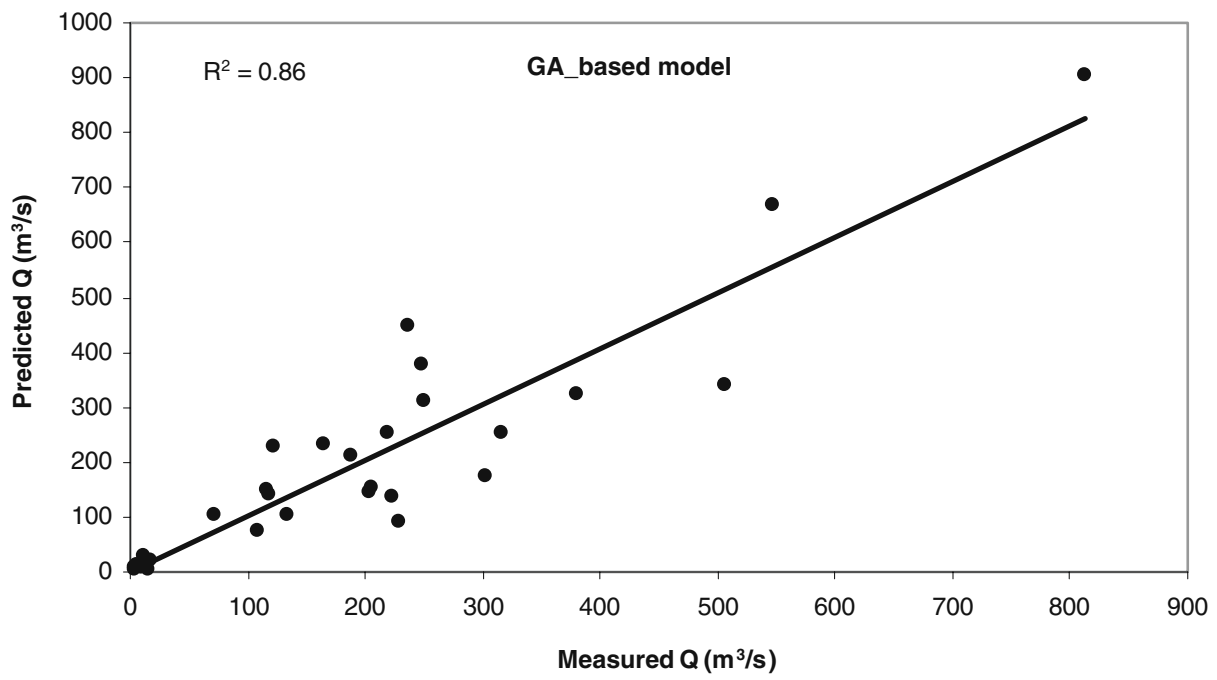

Fig. 3 Measured versus predicted mean discharge by the GA-based method 
bits [0 and 1] represents a parameter [or a decision variable] to be optimized. The combination of genes forms the chromosome each of which is a possible solution for each variable. Finally, set of chromosomes form the gene pool. The main GA operations basically consist of 'generation of initial gene pool', 'evaluation of fitness for each chromosome', 'selection', 'cross-over', and 'mutation'. Details of GA can be obtained from Goldberg (1989), Sen (2004), and Tayfur (2009), among others.

GA can minimize (or maximize) an objective function subject to specified constraints. For this study, GA was employed to obtain optimal values of the coefficients of (Eq. 1) using the same calibration data set [the set employed for obtaining the coefficients of Eq. 2] by minimizing the MAE objective function:

$$
M A E=\frac{1}{N} \sum_{i=1}^{N}\left|Q_{\text {pred }, i}-Q_{\text {meas }, i}\right|
$$

where $N$ is the number of observations; $Q_{\text {pred }}$ is the predicted discharge; and $Q_{\text {meas }}$ is the measured discharge.

Optimal values of parameters of Eq. 1 were found by employing 1000 iterations, 100 chromosomes, an $80 \%$ crossover rate and a $4 \%$ mutation rate. The trial version of evolver GA solver for Microsoft Excel (Palisade Corporation 2001) was employed, and the GA-based equation is obtained as:

$$
\log (Q)=1.1938 \log (A)-0.6296
$$

Appling the same procedure for the calibration data set of bankfull discharge, the following GA-based equation was obtained:

$$
\log (Q)=1.7274 \log (A)+0.0165
$$

Equations 5 and 6 were then applied to the verification data sets. Scatter diagrams of the predictions of the mean discharge and bankfull discharge, respectively, are

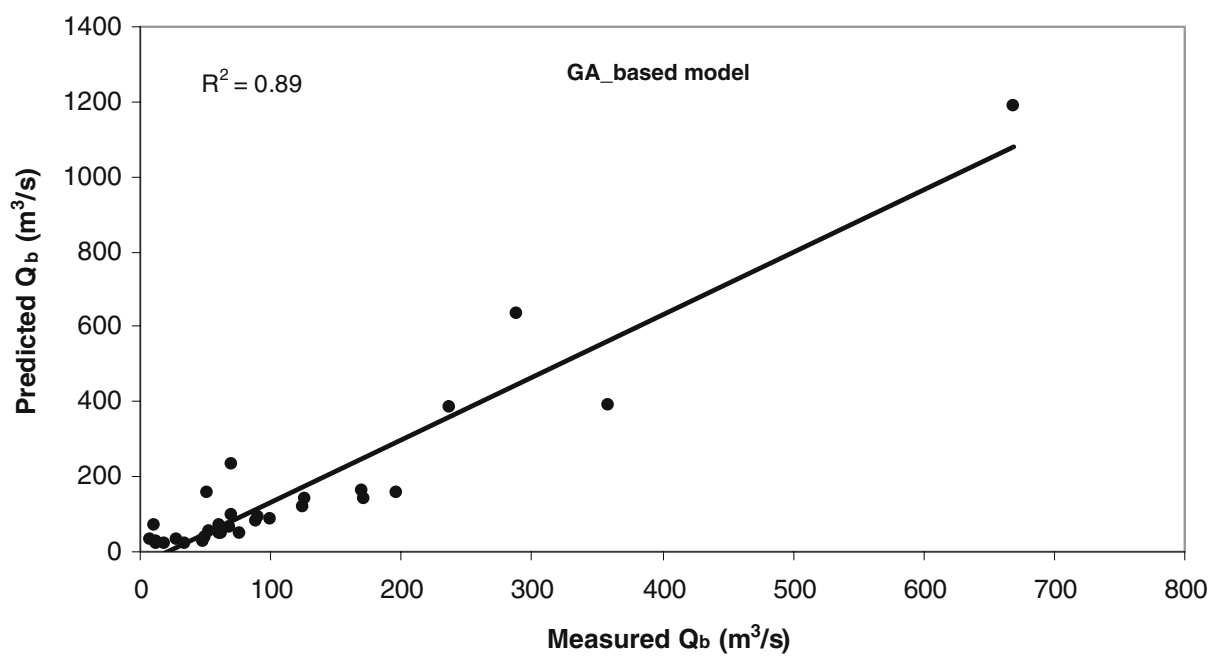

Fig. 4 Measured versus predicted bankfull discharge by the GA-based method 


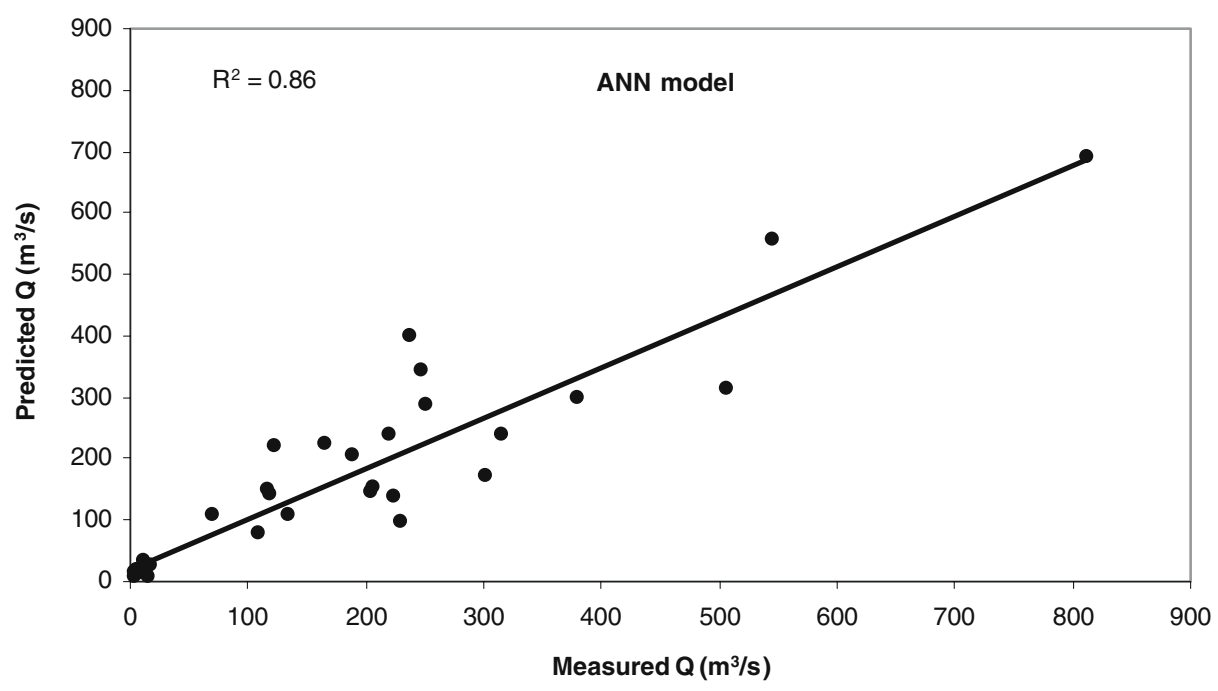

Fig. 5 Measured versus predicted mean discharge by the ANN method

presented in Figs. 3 and 4. Computed values of MAE, MRE, Accuracy, and $\mathrm{R}^{2}$ for these simulations are summarized in Table 3.

\subsection{Artificial Neural Networks Method}

An artificial neural network(ANN) is essentially a "black box" operation mapping input data onto output data using a particular set of nonlinear basis functions. Neurons, which are the basic units, are connected to each other by links known as synapses. Associated with each synapse, there is a weighting factor. Back propagation

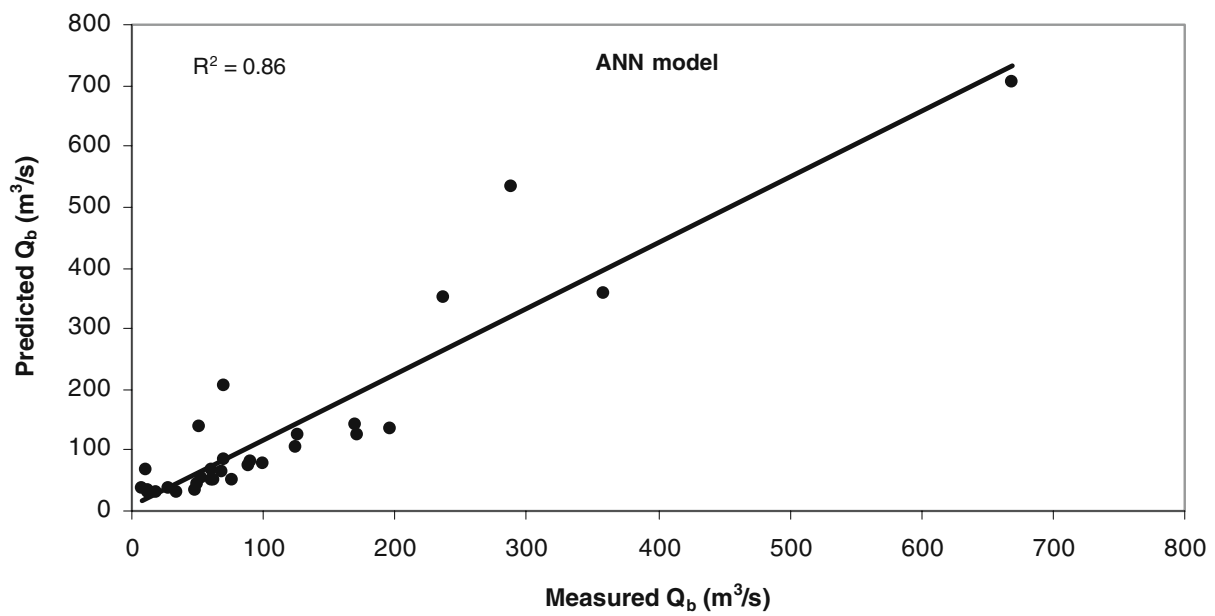

Fig. 6 Measured versus predicted bankfull discharge by the ANN method 
method is generally employed for training the feed-forward neural networks (FFNN) using a set of pairs of input and output values. Each neuron at input and inner layers receives input values, processes them and then passes the response to the next layer. The number of neurons in the input and output layers is determined by the numbers of input and output variables, respectively. The most commonly used network is a three-layer feed-forward ANN (ASCE 2000). Details on theoretical information about FFNN can be found in Haykin (1998), ASCE (2000), and Tayfur (2008).

In this present study, one-hidden-layer feed-forward artificial neural network using the sigmoid activation function was employed for predicting the mean and bankfull discharge from the corresponding cross sectional area. The constructed network for both the cases had 1-7-1 neurons in the input, hidden, and output layers, respectively. The number of neurons in the inner layer was obtained by a trial and error procedure. The networks were trained with 3,000 iterations, 0.01 learning rate and 0.02 momentum factor, employing the same calibration data sets (the same set used for obtaining Eqs. 2 and 5 for predicting the mean discharge and Eqs. 3 and 6 for predicting the bankfull discharge). The ANN yielded much better prediction results when it was trained with the original data rather than the log-transformed ones. Hence, as opposed to other methods, the original data were employed in training the

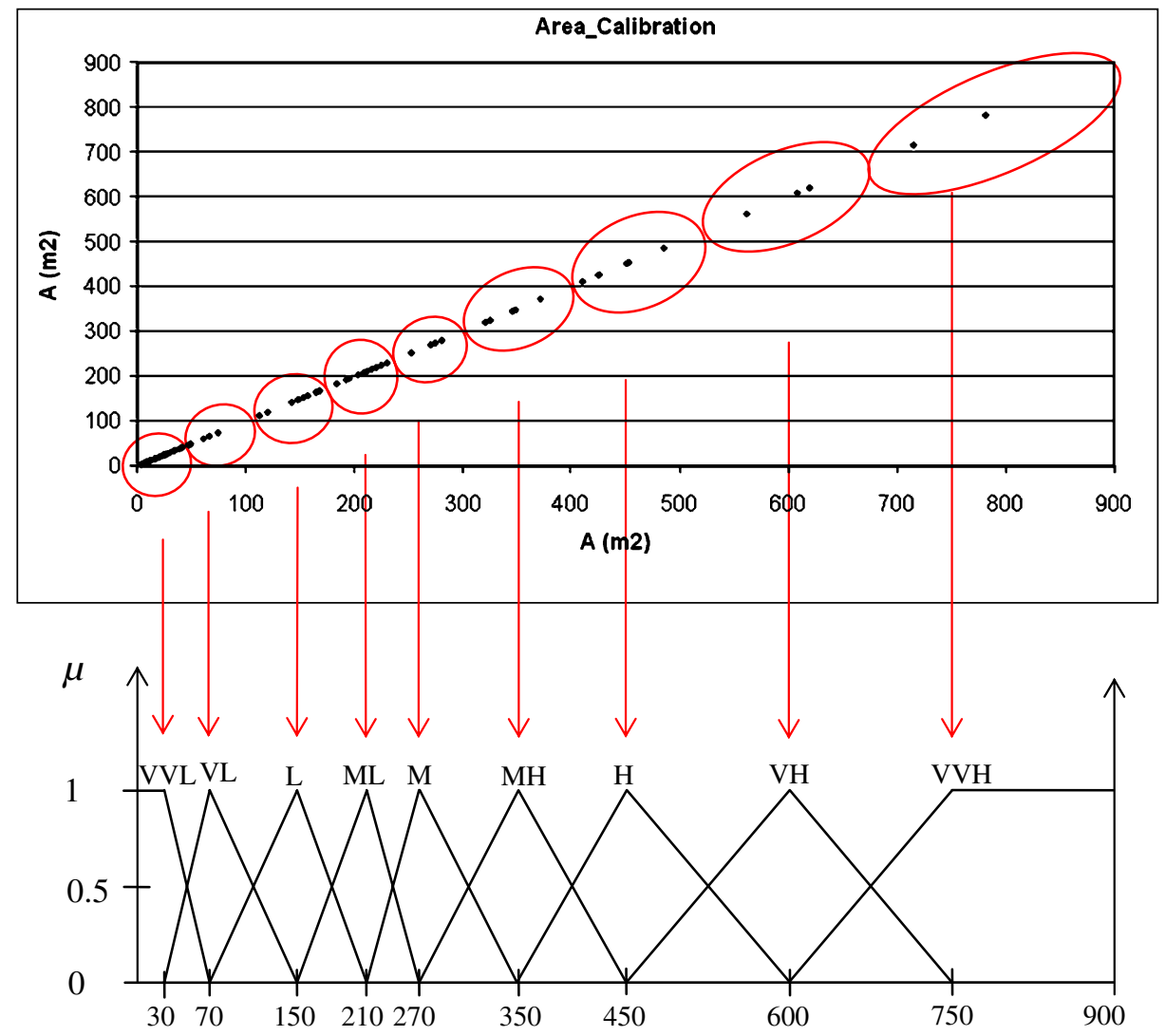

Fig. 7 Fuzzification of mean cross sectional area 
ANN method for both cases of mean discharge and bankfull discharge predictions. The trained networks were then tested for the verification data sets. Figures 5 and 6 , respectively, present predictions of mean discharge and bankfull discharge data by the trained ANNs methods. The computed values of error measures, accuracy, and $\mathrm{R}^{2}$ are summarized in Table 3 .

\subsection{Fuzzy Method}

For constructing the fuzzy method, first triangular and trapezoidal fuzzy subsets were decided, taking into account data clustering, as seen in Figs. 7 and 8. The clustering of data implies that the input variable mean cross-sectional area had nine subsets, and the output variable mean discharge had nine subsets. Likewise, from Figs. 9 and 10, the input variable of bankfull cross-sectional area had six subsets and the output variable bankfull discharge had six subsets. Following the methodology in Tayfur $(2006,2008)$, nine simple rules for mean discharge and six rules for bankfull discharge were constructed. These rules can be also intuitively written down. Each rule corresponded to each corresponding fuzzy subsets, e.g., IF $A$ is $M T H E N Q$ is $M$, where $M$ stands for 'medium'subsets; IF $A_{b}$ is $H$ THEN $Q_{b}$ is $H$, where $H$

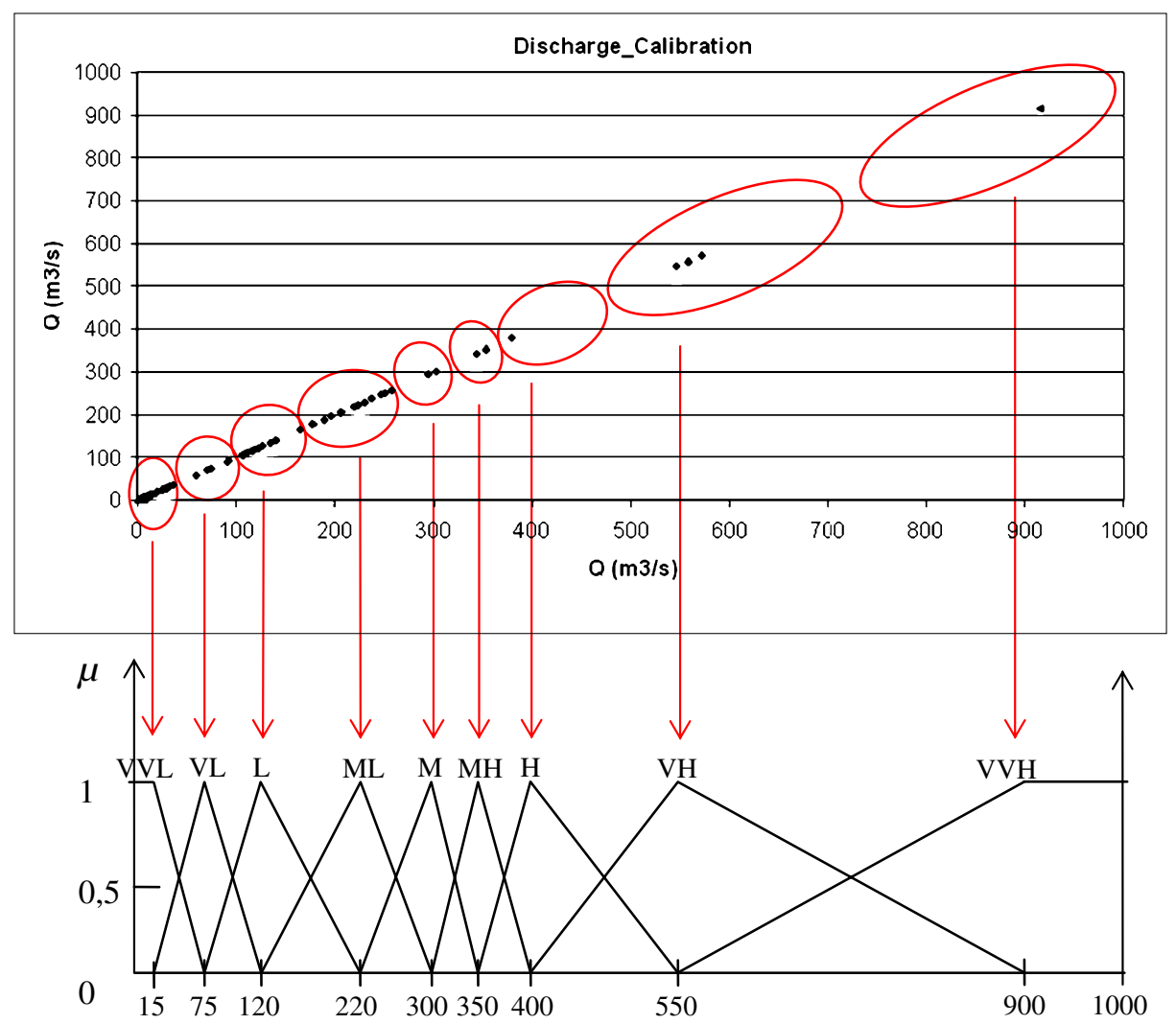

Fig. 8 Fuzzification of mean discharge 


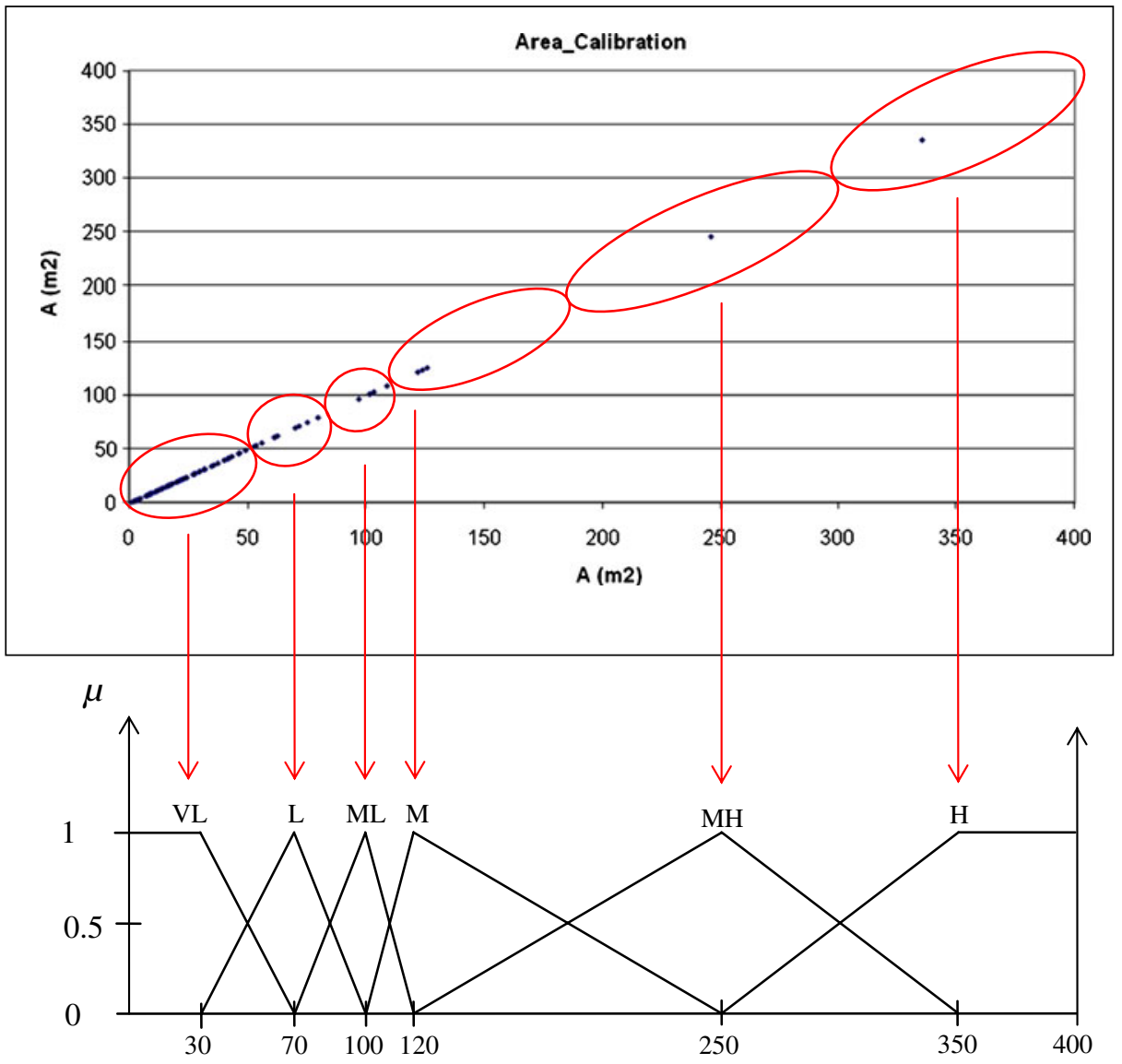

Fig. 9 Fuzzification of bankfull cross sectional area

stands for 'high' subsets. Details of the fuzzy method (fuzzification, fuzzy rule base, fuzzy inferencing and defuzzification) can be obtained elsewhere (Bardossy and Dissi 1993; Bardossy and Duckstein 1995; Sen 1998; Sen and Altunkaynak 2003; Tayfur 2006). The constructed fuzzy methods were then applied to the validation data sets, and predictions of mean discharge and bankfull discharge are, respectively, shown in Figs. 11 and 12. The computed values of MAE, MRE, Accuracy, and $\mathrm{R}^{2}$ are summarized in Table 3.

\section{Discussion of the Results}

As seen from Figs. 1, 3, 5 and 11, all methods were able to predict mean discharge, including low and high values. As summarized in Table 3, the non-linear regression, GA-based non-linear equation, and ANN methods produced comparable minimum errors in predicting mean discharge, with $\mathrm{R}^{2}=0.86$. The GA-based method produced 


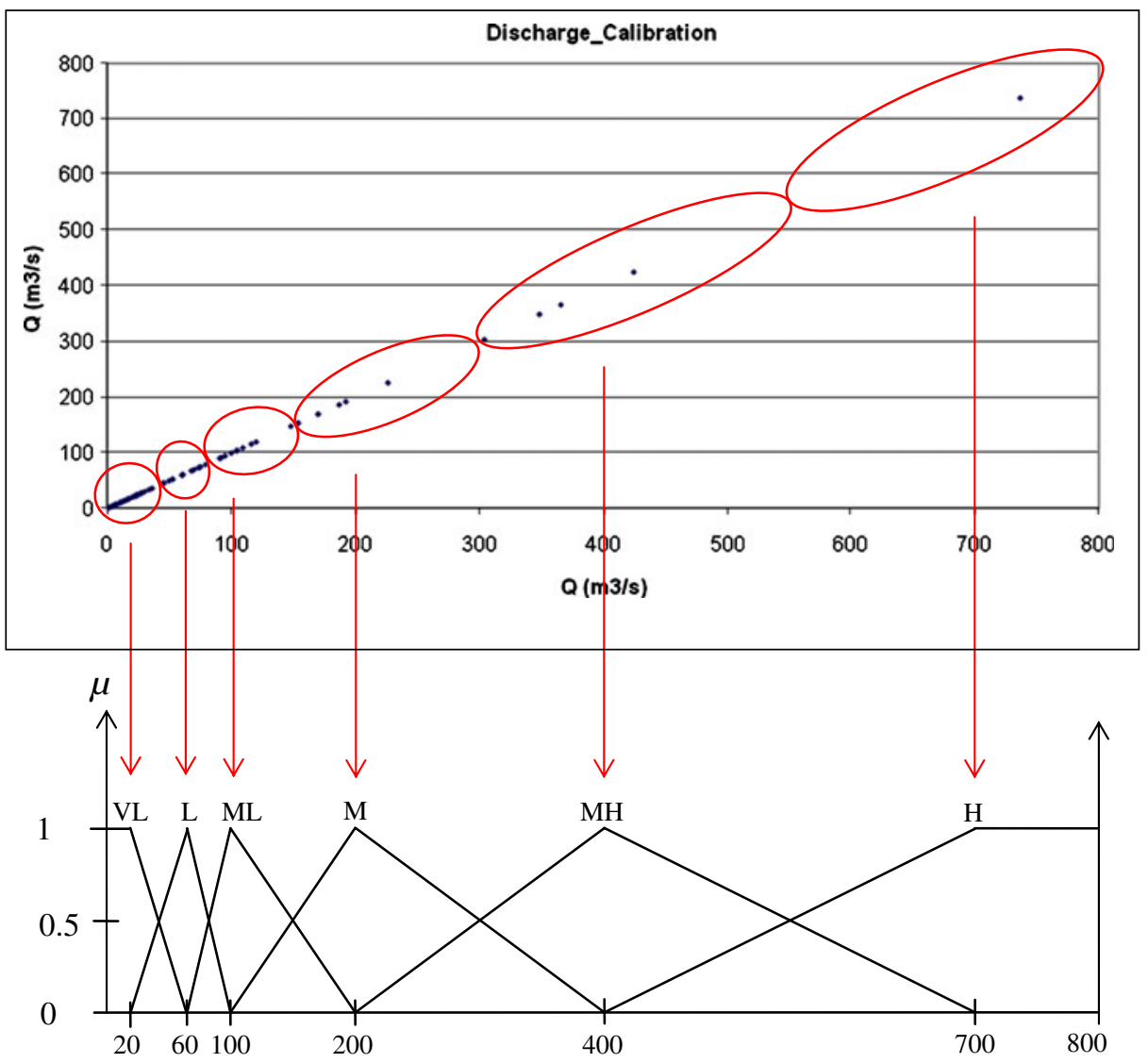

Fig. 10 Fuzzification of bankfull discharge

the highest accuracy rate of $75 \%$, followed by the non-linear regression and ANN methods. The fuzzy method, on the other hand, although had high $\mathrm{R}^{2}=0.81$ and low MAE of about $64 \mathrm{~m}^{3} / \mathrm{s}$, produced MRE of about $140 \%$ and low accuracy of $40 \%$.

For bankfull discharge predictions, including the low and high values, shown in Figs. 2, 4, 6 and 12, all methods performed satisfactorily. Yet, as seen from Table 3, although the non-linear regression, GA-based, and ANN methods produced comparable values of low MAE, MRE, and high $\mathrm{R}^{2}$ and accuracy, the fuzzy method showed high error and low accuracy. The ANN method produced the highest accuracy rate of $73 \%$, followed by the non-linear regression and GA-based methods. The fuzzy method produced the minimum accuracy rate of $33 \%$.

\subsection{Sensitivity Analysis}

To investigate the extrapolation capability of the method; the developed models calibrated with low discharge data were applied to predict high discharges. This is 


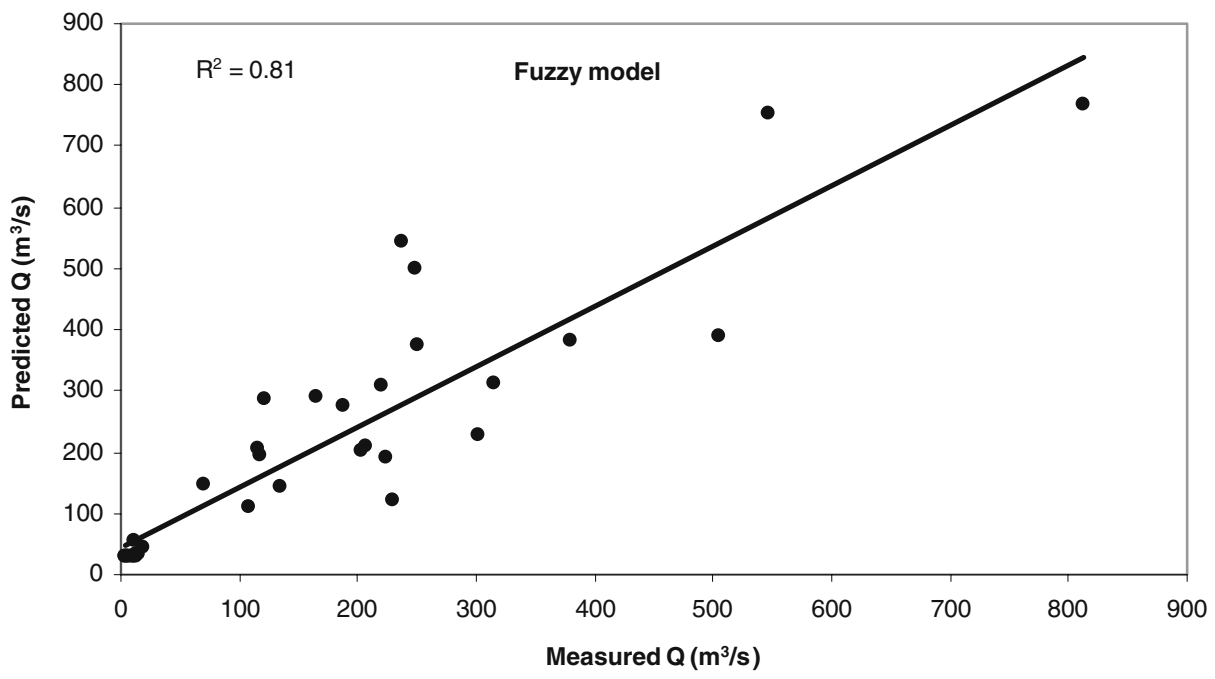

Fig. 11 Measured versus predicted mean discharge by the Fuzzy method

important for predicting flows at ungauged sites. In their study, Tayfur et al. (2007) trained several networks with hydrographs having low peaks for predicting high-peak hydrographs, and showed that ANNs were poor extrapolators, agreeing with the literature. Hence, in this study, ANNs were not included in the sensitivity analysis. The fuzzy method also cannot be included in the analysis, because constructing fuzzy subsets for low range values and then predicting high values would not be possible. For example, as seen in Figs. 7 and 8, the highest value for $A$ and $Q$ are $900 \mathrm{~m}^{2}$ and $1,000 \mathrm{~m}^{3} / \mathrm{s}$, respectively. Also, it is clear that from Figs. 7 and 8 , for any value of

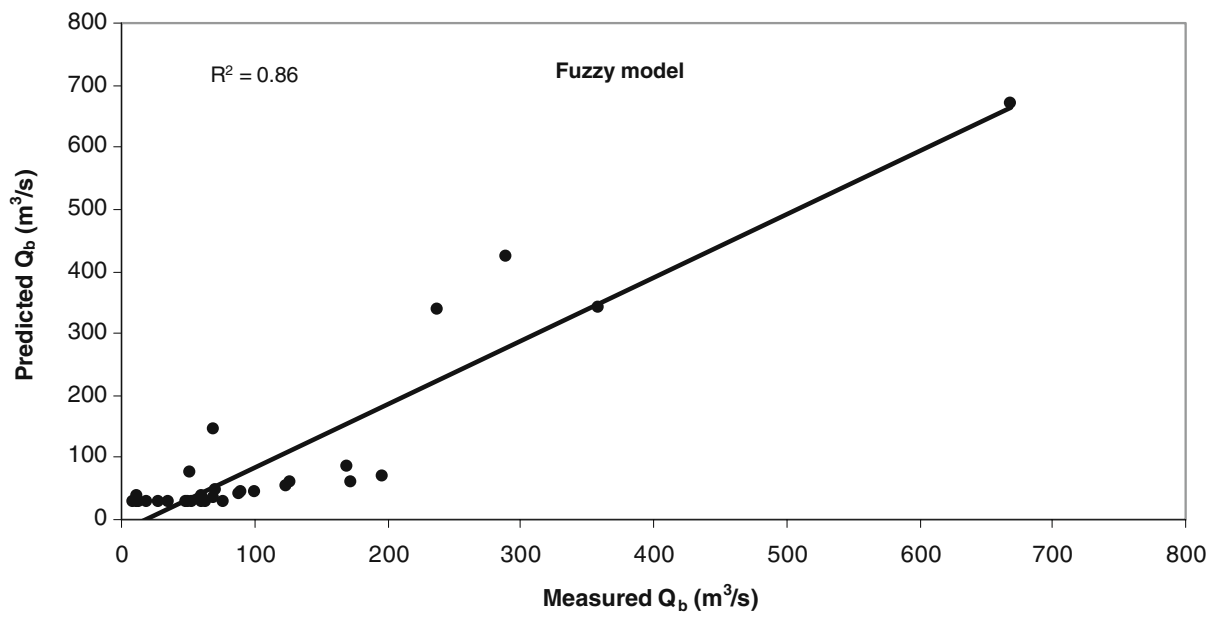

Fig. 12 Measured versus predicted mean discharge by the Fuzzy method 
Table 4 Scenarios and performance of the methods for the case of bankfull discharge data

\begin{tabular}{|c|c|c|c|c|c|c|}
\hline \multirow[b]{2}{*}{ Scenario number } & \multirow[b]{2}{*}{ Calibration set } & \multirow[b]{2}{*}{ Verification set } & \multicolumn{2}{|c|}{ Regression method } & \multicolumn{2}{|c|}{ GA-based method } \\
\hline & & & MRE \% & Accuracy \% & MRE \% & Accuracy \% \\
\hline$\# 1$ & $\begin{array}{l}\mathrm{Q}_{\mathrm{b}}<50 \mathrm{~m}^{3} / \mathrm{s} \\
\quad(34 \text { data sets) }\end{array}$ & $\begin{array}{r}\mathrm{Q}_{\mathrm{b}}>100 \mathrm{~m}^{3} / \mathrm{s} \\
(28 \text { data sets })\end{array}$ & 70 & 3 & 65 & 4 \\
\hline \#2 & $\begin{array}{r}\mathrm{Q}_{\mathrm{b}}<100 \mathrm{~m}^{3} / \mathrm{s} \\
\quad(63 \text { data sets })\end{array}$ & $\begin{array}{r}\mathrm{Q}_{\mathrm{b}}>200 \mathrm{~m}^{3} / \mathrm{s} \\
\quad(10 \text { data sets })\end{array}$ & 32 & 50 & 26 & 80 \\
\hline \#3 & $\begin{array}{r}\mathrm{Q}_{\mathrm{b}}<200 \mathrm{~m}^{3} / \mathrm{s} \\
\quad(79 \text { data sets })\end{array}$ & $\begin{array}{c}\mathrm{Q}_{\mathrm{b}}>400 \mathrm{~m}^{3} / \mathrm{s} \\
(3 \text { data sets })\end{array}$ & 20 & 100 & 15 & 100 \\
\hline
\end{tabular}

$A \geq 750 \mathrm{~m}^{2}$, the method would not produce any value greater than $Q=900 \mathrm{~m}^{3} / \mathrm{s}$. This means that even, let us say, $A=1,200 \mathrm{~m}^{2}$, the method will at most produce $Q=900 \mathrm{~m}^{3} / \mathrm{s}$. Therefore, only the non-linear regression and GA-based methods were considered for the extrapolation sensitivity analysis.

The non-linear regression and GA-based methods were calibrated with low discharge data and tested for high values. Three different scenarios were conceptualized, as shown in Tables 4 and 5, respectively, for the bankfull discharge, and mean discharge cases. In the first scenario, the methods were calibrated with data sets whose discharge values were less than $50 \mathrm{~m}^{3} / \mathrm{s}$ and then tested for discharge values greater than $100 \mathrm{~m}^{3} / \mathrm{s}$. In the second scenario, the methods were calibrated with $Q<100 \mathrm{~m}^{3} / \mathrm{s}$ and then tested for $Q>200 \mathrm{~m}^{3} / \mathrm{s}$. Finally, the methods were calibrated with $Q<200 \mathrm{~m}^{3} / \mathrm{s}$ data and then tested for $Q>400 \mathrm{~m}^{3} / \mathrm{s}$. The performances of methods are summarized in Tables 4 and 5 that also show the number of data sets used in each scenario. In the case of the models' performance of extrapolation capability for predicting bankfull discharge data as seen in Table 4, neither of the methods performed well when calibrated with data whose maximum discharge were $50 \mathrm{~m}^{3} / \mathrm{s}$. Yet, when they were calibrated with data whose discharge values were less than $100 \mathrm{~m}^{3} / \mathrm{s}$, it was clearly seen that the GA-based method satisfactorily predicted discharge values of $Q>200 \mathrm{~m}^{3} / \mathrm{s}$ with $26 \%$ MRE and $80 \%$ accuracy, as opposed to the non-linear regression method whose $\mathrm{MRE}=32 \%$ and accuracy $=50 \%$. In the last scenario, the GA-based method performed slightly better. Note that, in this last scenario, there were only three data (very few) to predict and hence, the performance measures would not be reliable. With regard to the extrapolation capability of the models for predicting mean discharge data as shown in Table 5, neither method performed satisfactorily.

Table 5 Scenarios and performance of the methods for the case of mean discharge data

\begin{tabular}{|c|c|c|c|c|c|c|}
\hline \multirow[b]{2}{*}{ Scenario number } & \multirow[b]{2}{*}{ Calibration set } & \multirow[b]{2}{*}{ Verification set } & \multicolumn{2}{|c|}{ Regression method } & \multicolumn{2}{|c|}{ GA-based method } \\
\hline & & & MRE \% & Accuracy \% & MRE \% & Accuracy \% \\
\hline \#1 & $\begin{array}{l}\mathrm{Q}<50 \mathrm{~m}^{3} / \mathrm{s} \\
(47 \text { data sets })\end{array}$ & $\begin{array}{l}\mathrm{Q}>100 \mathrm{~m}^{3} / \mathrm{s} \\
\quad(52 \text { data sets })\end{array}$ & 73 & 0.0 & 68 & 4.0 \\
\hline \#2 & $\begin{array}{l}\mathrm{Q}<100 \mathrm{~m}^{3} / \mathrm{s} \\
\quad(56 \text { data sets) }\end{array}$ & $\begin{array}{l}\mathrm{Q}>200 \mathrm{~m}^{3} / \mathrm{s} \\
\quad(34 \text { data sets) }\end{array}$ & 56 & 15 & 69 & 10.0 \\
\hline \#3 & $\begin{array}{l}\mathrm{Q}<200 \mathrm{~m}^{3} / \mathrm{s} \\
\quad(74 \text { data sets })\end{array}$ & $\begin{array}{l}\mathrm{Q}>400 \mathrm{~m}^{3} / \mathrm{s} \\
(7 \text { data sets })\end{array}$ & 46 & 43 & 55 & 35.0 \\
\hline
\end{tabular}




\section{Summary and Conclusions}

This study employs nonlinear regression, GA-based nonlinear regression, ANN and Fuzzy methods for predicting mean discharge and bankfull discharge from cross sectional area. Area-discharge data are compiled from the literature and separated into calibration and testing sets. About $65 \%$ of the data are used for calibration and the remaining $35 \%$ for testing of the methods. Nonlinear regression, GA-based, and ANN methods can be confidently employed for predicting mean discharge and bankfull discharge while the fuzzy method requires caution.

Results of sensitivity analysis show that the GA-based method can be confidently employed to predict bankfull discharges at ungauged sites. The method calibrated with 60 sets of data and maximum discharge value of $100 \mathrm{~m}^{3} / \mathrm{s}$ is able to predict high values of $Q>200 \mathrm{~m}^{3} / \mathrm{s}$ up to $Q=750 \mathrm{~m}^{3} / \mathrm{s}$. It should be also noted that the GAbased method calibrated with 28 sets and maximum $Q<50 \mathrm{~m}^{3} / \mathrm{s}$ is not able to predict high values of $Q>100 \mathrm{~m}^{3} / \mathrm{s}$. This implies that in order to predict high values, the GA-based method should be calibrated with sufficient number of discharge values. This study shows that the bankfull cross-section area measurement is all that may be needed to estimate the bankfull discharge at ungauged river sites. On the other hand, it may be stated that the extrapolation capabilities of GA-based and nonlinear regression methods are poor for predicting the mean discharge data used in this study.

The mean cross sectional area in this study varies from about 10 to $1,000 \mathrm{~m}^{2}$, with a mean value of about $200 \mathrm{~m}^{2}$. Similarly, the bankfull cross sectional area varies, on the average, between 10 and $400 \mathrm{~m}^{2}$ with a mean of about $50 \mathrm{~m}^{2}$. The corresponding mean discharge values are almost in between $5-900 \mathrm{~m}^{3} / \mathrm{s}$, with $150 \mathrm{~m}^{3} / \mathrm{s}$ mean value. Similarly, the range for the bankfull discharge varies in between $5-750 \mathrm{~m}^{3} / \mathrm{s}$, with $100 \mathrm{~m}^{3} / \mathrm{s}$ mean value. When applying one of the methods for predicting discharge, the range of cross-sectional data should be taken into account. In other words, these methods may not be applied to cases where the cross-sectional and discharge data are too small $\left(A<1 \mathrm{~m}^{2}, Q<1 \mathrm{~m}^{3} / \mathrm{s}\right.$, as it is the case in Afzalimehr et al. 2009) or too extreme. In such cases, it would be necessary to recalibrate and re-validate the methods.

\section{References}

Afzalimehr H, Singh VP, Abdolhosseini M (2009) Effect of nonuniformity of flow on hydraulic geometry relations. J Hydrol Eng 14(9):1028-1034

Akbari FM, Afshar A, Sadrabadi MR (2009) Fuzzy rule based models modification by new data: application to flood flow forecasting. Water Resour Manag 23(12):2491-2504

ASCE (2000) Artificial neural networks in hydrology. I: preliminary concepts. J Hydrol Eng, ASCE 5(2):115-123

Bardossy A, Dissi M (1993) Fuzzy rule-based methods for infiltration. Water Resour Res 29(2): 373-382

Bardossy A, Duckstein L (1995) Fuzzy rule-based methoding with applications to geophysical, biological and engineering systems. CRC, New York

Bhatt VK, Tiwari AK (2008) Estimation of peak streamflows through channel geometry. Hydrol Sci J 53(2):401-408

Chen CH, Chou FN-F, Chen BP-T (2010) Spatial information-based back-propagation neural network modeling for outflow estimation of ungauged catchment. Water Resour Manag 24: 4175-4197 
Engeland K, Hisdal H (2009) A comparison of low flow estimates in ungauged catchments using regional regression and the HBV-model. Water Resour Manag 23(12):2567-2586

Eslamian S, Ghasemizadeh M, Biabanaki M, Talebizadeh M (2010) A principal component regression method for estimating low flow index. Water Resour Manag 24(11):2553-2566

Goldberg DE (1989) Genetic algorithms for search, optimization, and machine learning. AddisonWesley, New York

Haykin S (1998) Neural networks-a comprehensive foundation, 2nd edn. Prentice-Hall, Upper Saddle River, pp 26-32

Hey RD, Thorne CR (1986) Stable channels with mobile gravel beds. J Hydraul Eng 112(8):671-689

Palisade Corporation (2001) Evolver, the genetic algorithm solver for microsoft excel. Palisade Corporation, Newfield

Sen Z (1998) Fuzzy algorithm for estimation of solar irradiation from sunshine duration. Sol Energy 63(1):39-49

Sen Z (2004) Genetic algorithm and optimization methods. Su Vakfi Yayinlari, Istanbul. (Turkish). ISBN: 975-6455-12-8

Sen Z, Altunkaynak A (2003) Fuzzy awakingning in rainfall-runoff methodling. Nord Hydrol 35(1):31-43

Tayfur G (2006) Fuzzy, ANN, and Regression Methods to Predict Longitudinal Dispersion Coefficient in Natural Streams. Nord Hydrol 37(2)

Tayfur G (2008) Soft computing approaches in hydrology. In: Singh VP (ed) Hydrology and hydraulics. Water Resources Publications, LLC, Colorado, pp 113-144

Tayfur G (2009) GA-optimized method predicts dispersion coefficient in natural channels. Hydrology Research 40(1):65-78

Tayfur G, Moramarco T, Singh VP (2007) Predicting and forecasting flow discharge at sites receiving significant lateral inflow. Hydrol Process 21:1848-1859

Wahl KL (1984) Evolution of the use of channel cross section characteristics for estimating streamflow characteristics. US Geol. Survey Water Supply Paper no. 2262, Washington DC, USA, pp 53-66

Wharton G (1995) The channel-geometry method: guidelines and applications. Earth Surf Process Landf 20:649-660

Wharton G, Tomlinson JJ (1999) Flood discharge estimation from river channel dimensions: results of applications in Java, Burundi, Ghana and Tanzania. Hydrol Sci J 44(1):1-17

Wharton G, Arnell NW, Gregory KJ, Gurnell AM (1989) River discharge estimated from river channel dimensions. J Hydrol 106:365-376

Williams GP (1978) Bank-Full discharge of rivers. Water Resour Res 14(6):1141-1154

Zhu Y-Y, Zhou H-C (2009) Rough fuzzy inference model and its application in multi-factor medium and long-term hydrological forecast. Water Resour Manag 23(3):493-507 